\title{
Conselho do FUNDEB no DF: missão quase impossível!
}

\section{FUNDEB council in the Federal District: almost an impossible mission! Ayuntamiento del fUNDEB en el Distrito Federal: ¡misión casi imposible!}

\author{
FRANCISCO JOSÉ DA SILVA \\ http://orcid.org/0000-0002-5624-3779 \\ Secretaria de Estado de Educação do Distrito Federal \\ Escola de Aperfeiçoamento dos Profissionais da Educação \\ Brasília, DF, Brasil
}

\begin{abstract}
Resumo: O objetivo desse artigo é discutir as limitações do Conselho do Fundeb do Distrito Federal para realizar o acompanhamento e controle social dos recursos financeiros do Fundo, do Programa Nacional de Apoio ao Transporte Escolar e do Plano de Ações Articuladas. Utilizou-se principalmente legislação referente às atribuições do Conselho e documentos produzidos por ele. O estudo indica a necessidade do Conselho concentrar as suas ações no acompanhamento e controle social, e não na fiscalização, uma vez que esta é de competência dos órgãos de fiscalização.
\end{abstract}

Palavras-chave: Controle social. Recursos financeiros. Órgão de fiscalização.

\begin{abstract}
The purpose of this article is to discuss the limitations of the Fundeb Council of the Federal District to carry out the monitoring and social control of the Fund's financial resources, the National Support Program for School Transportation, and the Plan of Articulated Actions. It was used mainly legislation regarding the attributions of the Council and documents produced by it. The study indicates the need for the Council to concentrate its actions on monitoring and social control, and not on inspection, since this is the responsibility of the supervisory bodies.
\end{abstract}

Keywords: Social control. Financial resources. Supervisory body.

Resumen: El objetivo de este artículo es discutir las limitaciones del Concejo de Fundeb del Distrito Federal para realizar el seguimiento y control social de los recursos financieros del Fondo, del Programa Nacional de Apoyo al Transporte Escolar y del Plan de Acciones Articuladas. Se utilizó principalmente legislación sobre las atribuciones del Concejo y documentos producidos por el mismo. El estudio indica la necesidad de que el Ayuntamiento concentre sus acciones en el seguimiento y control social, y no en la fiscalización, ya que esta es responsabilidad de los órganos de control.

Palabras clave: Control social. Recursos financieros. Órgano de control. 


\section{INTRODUÇÃO}

Discute-se nesse artigo as limitações do Conselho de Acompanhamento e Controle Social do Fundo de Manutenção e Desenvolvimento da Educação Básica e de Valorização dos Profissionais da Educação do Distrito Federal (CACS-FUNDEB/DF) em atuar na realização do acompanhamento e controle social $\left(\mathrm{ACS}^{1}\right.$ ) de parte dos recursos financeiros da educação, mais especificamente no que se refere aos recursos financeiros do FUNDEB; do Programa Nacional de Apoio ao Transporte Escolar (PNATE); do Plano de Ações Articuladas (PAR). Sustenta-se que as tais limitações têm relação direta com o equívoco de se colocar a fiscalização - que é própria do controle administrativo interno, Tribunais, Controladorias, Ministérios Públicos e afins - como foco das ações do CACSFUNDEB/DF.

Obviamente, existem pontos convergentes entre o acompanhamento e controle social (ACS) e a fiscalização, em especial quando esse processo envolve recursos financeiros, mas ao mesmo tempo não faz sentido tê-los como sinônimos. É que a fiscalização como substituta do ACS pode conduzir o CACS para atividades alheias à sua natureza e com isso esvaziá-lo como espaço de participação social.

Em termos metodológicos, recorreu-se principalmente às legislações que estabelecem as atribuições do Conselho e documentos produzidos por este, no âmbito do Distrito Federal, no período de março de 2018 a outubro de 2020. Foi realizada também breve análise bibliográfica de estudos que citam o termo fiscalização como sinônimo de ACS. As Legislações consideradas foram: Lei Federal n. ${ }^{\circ}$ 9.424/1996; Lei Federal n. ${ }^{\circ}$ 11.494/2007, em especial o capítulo VI que trata do acompanhamento, controle social, comprovação e fiscalização dos recursos; Lei Complementar Distrital n. ${ }^{\circ}$ 793/2008 (LC n. ${ }^{\circ}$ 793/2008), que cria o CACS do DF; Lei Federal n. ${ }^{\circ}$ 10.880/2004, que institui o PNATE; a Resolução FNDE n. ${ }^{\circ}$ 05/2020, que estabelece os critérios e as formas de transferência de recursos financeiros do PNATE; Lei Federal no 12.695/2012, que dispõe sobre o apoio técnico ou financeiro da União no âmbito do PAR; projetos de lei n. ${ }^{\circ}$ 4372/2020 (Câmara Federal) e n. ${ }^{\circ}$ 4519/2020 (Senado Federal) ${ }^{2}$, que tratam da regulamentação do novo FUNDEB. Também foram considerados os documentos produzidos pelo CACS-FUNDEB/DF: atas das reuniões ordinárias; relatórios de visitas aos centros de educação da primeira infância (CEPI) e de averiguação das condições dos ônibus contratados pela Secretaria de Estado de Educação do

\footnotetext{
1 Adotar-se-á a sigla ACS ao longo do texto em alguns momentos para se referi ao acompanhamento e controle social.

2 Esse artigo foi concluído e enviado para avaliação em outubro de 2020.
}

1280 - Rev. Bras. Polít. Adm. Educ. - v. 37, n. 3, p. 1279 - 1299, set./dez. 2021 
Distrito Federal (SEEDF) que transportam estudantes; ofícios emitidos. Além disso, levou-se em consideração, ainda que de forma indireta, os registros do caderno de anotações do autor desse artigo elaborado durante participação nas reuniões ordinárias do CACS e conversas realizadas nas visitas aos centros de educação da primeira infância (CEPI) em 2019.

A seleção de documentos de diferentes naturezas se deve à complexidade de identificar de maneira mais clara a presença da fiscalização em detrimento do acompanhamento e controle social.

O artigo está organizado em quatro tópicos. O primeiro, intitulado Acompanhamento e Controle Social versus Fiscalização, inicia-se com um brevíssimo esclarecimento acerca da concepção de controle social adotada, no caso uma que não se alinha à submissão dos membros de uma sociedade às normas existentes. São apresentadas algumas produções que tratam do CACS para mostrar como a categoria fiscalização está presente e o risco desta enfraquecer o propósito desse conselho no âmbito do ACS.

O segundo tópico, Acompanhamento e Controle Social dos Recursos do Fundeb: missão quase impossivel 1, procura mostrar que, apesar da Lei do Fundeb especificar de forma razoável os poderes do CACS em termos de solicitação de documentos referentes à execução dos recursos do Fundo, o formato de relatório elaborado pelo Governo do Distrito Federal (GDF) e sobre o qual o CACS deve emitir parecer é incompatível com a lógica do ACS.

Já no terceiro tópico, Acompanhamento e Controle Social dos Recursos do PNATE: missão quase impossivel 2, são destacadas algumas dificuldades no que tange à emissão de parecer conclusivo pelo CACS acerca da aplicação dos recursos repassados à conta do PNATE, tais como: execução conjunta dos recursos do programa e das receitas próprias do GDF, o que inviabiliza a identificação do que foi usado para o transporte de alunos residentes em área rural; ausência de garantias na Lei Federal n. ${ }^{\circ}$ 11.494/2007 que respaldem certo nível de ACS; a confusão nas resoluções do FNDE em relação à exclusividade de transporte de alunos residentes em área rural; documentos extremamente técnicos e disponibilizados para emissão de parecer apenas depois que o GDF envia a prestação de contas para o FNDE.

Por fim, o quarto e último tópico, Acompanbamento e Controle Social dos Recursos do PAR: missão quase impossivel 3, discute os recursos repassados via PAR. Procura-se indicar que, embora o CACS tenha acesso a muitas informações junto ao Sistema Integrado de Monitoramento Execução e Controle do Ministério da Educação (Simec), é quase impossível realizar o ACS por essa via, não apenas em 
função quantidade de termos de compromisso em vigência, complexidade que se multiplica com as várias reprogramações, mas também devido à linguagem extremamente técnica das telas disponibilizadas.

\section{ACOMPANHAMENTO E CONTROLE SOCIAL VERSUS FISCALIZAÇÃO}

Em primeiro lugar, é importante esclarecer que controle social não é entendido aqui como "intervenção da sociedade ou grupo social a fim de induzir os próprios membros a se conformarem às normas que a caracterizam, de impedir e desestimular os comportamentos contrários às mencionadas normas (...)" (GARELLI, 1986, 283).

O controle social tido como referência nesse estudo é do tipo que empodera a sociedade civil, nesse caso específico, para lidar com parte dos recursos da educação via Conselho do FUNDEB.

Em segundo lugar, o termo fiscalização não pode ser tido como sinônimo de acompanhamento e controle.

\footnotetext{
"Controle, fiscalização e acompanhamento tomam um sentido muito próximo quando nos referimos aos conselhos sociais que atuam no controle social da administração pública. No entanto, esses termos não são sinônimos, embora muitas vezes sejam colocados em um mesmo patamar" (UMANN, 2018, p33).
}

Segundo o Dicionário Priberam, fiscalização "é o ato, efeito ou encargo de fiscalizar" (2020). Já o Dicionário Online de Português é mais direto ao afirmar que fiscalização "é o ato ou efeito de fiscalizar... [e] cargo ou exercício de fiscal" (2020). Nesse sentido, cabe o seguinte questionamento: o Conselho do FUNDEB tem condições de atuar na fiscalização e o conselheiro de exercer as atribuições de um fiscal? Como base na experiência do CACS do DF, pelo menos de setembro de 2018 a outubro de 2020, a resposta a essa perguntas é negativa.

Vale registrar que, de acordo com a Lei 11.494 de 2007,

\footnotetext{
"os conselhos dos Fundos não contarão com estrutura administrativa própria, incumbindo à União, aos Estados, ao Distrito Federal e aos Municípios garantir infra-estrutura e condições materiais adequadas à execução plena das competências dos conselhos...” (\$ 10 , inciso $\mathrm{V}$, art. 24). (grifo meu)
}

Ora, se não existe previsão legal para a tal estrutura administrativa própria, como esperar que os conselhos em pauta tenham como encargo a fiscalização? E mais do que isso: como esperar que os conselheiros realizem ação fiscalizadora? 
E colocar em dúvida tudo isso não pretende desqualificar a participação da sociedade, e sim fortalecê-la, mas no âmbito do acompanhamento e controle social. Sim, pois dos 9 (nove) membros do CACS, 5 (cinco) são representantes da sociedade (estudantes, pais e profissionais da educação) que trazem experiência diferenciadas no campo da educação básica pública e que precisam ser bem aproveitadas nessa complexa atribuição de lidar com recursos financeiros.

Portanto, o controle social adotado e defendido nesse estudo afastase da compreensão clássica de controle social como instrumento limitador da participação das pessoas e difere da categoria fiscalização por entendê-la inadequada para os desafios do CACS-FUNDEB. Ou Seja, entende-se o controle social não como o controle do estado sobre o coletivo, e sim de um coletivo, nesse caso específico o CACS, sobre parte dos recursos públicos da educação. Obviamente, existirão pontos de articulação e conexão entre o acompanhamento e controle social do CACS e a fiscalização.

Vale destacar que, embora a intenção de muitos estudos seja a de fortalecer os conselhos, o uso do termo fiscalização como sinônimo de ACS pode ajudar a esvaziar a natureza do CACS, ainda que o objetivo seja o contrário. Acredita-se que essa discussão poderá contribuir para que, no futuro, a fiscalização, em especial no que se refere à sua dimensão meramente técnica, se restrinja ao seu lugar, no caso junto aos órgãos de controle. Tal afirmação, vale enfatizar com veemência, não pressupõe distanciamento e negação de diálogo constante entre o CACS e os órgãos de controle, e muito menos que os conselhos não compreendam os mecanismos de fiscalização, seja do ponto de vista legal, seja em relação aos detalhes contidos em sistemas informatizados de monitoramento; pelo contrário, é preciso exigir que os governos disponibilizem ao CACS assessoria técnica para que esses processos de fiscalização sejam muito bem compreendidos. Contudo, isso é diferente de assumir a atribuição de fiscalizar. A ideia é que se tenha clareza acerca das atribuições do CACS e dos órgãos de controle em relação aos recursos do Fundeb, do PNATE e do PAR, até porque a garantia do direito à educação pública de qualidade não pode prescindir da fiscalização realizada mais diretamente pelos órgãos de controle e do acompanhamento e controle social que deve ser assumido pelo CACS.

Serão apresentadas a seguir algumas produções que tratam do assunto em pauta, de forma a mostrar como o termo fiscalização está presente quando o CACS-Fundeb é abordado.

Madureira e Gouveia sustentam que

"há potencialidade nesses conselhos em promover uma fiscalização concreta de parcela importante dos recursos da educação, desde que superadas as restrições legais e políticas que permeiam sua atuação" (2019, p. 7). (grifo meu) 
Tal lógica é reforçada pela afirmação do deputado Tadeu Veneri, que foi entrevistado pelas pesquisadoras, ao sustentar que o Fórum

\begin{abstract}
"possui um potencial de conscientização sobre a fiscalização dos recursos da educação, mas que ainda pode ser melhorado no sentido de torná-lo um espaço mais politizado, com as pessoas mais conscientes sobre o papel do controle e fiscalização dos recursos públicos" (MADUREIRA e GOUVEIA, 2019, p. 6). (grifo meu)
\end{abstract}

Atente-se que, embora o deputado sustente corretamente a importância de tornar o Fórum espaço politizado, o foco é colocado no controle e na fiscalização dos recursos públicos, e não no ACS. De qualquer forma, como a discussão das autoras é sobre o Fórum, o qual tem a presença até mesmo de órgãos de controle, o uso do termo fiscalização talvez faça algum sentido.

Borba, por sua vez, apresenta uma pergunta que sintetiza bem o desafio em discussão: "Quais os limites e possibilidades da atuação do [CACS] enquanto instância de participação?” (2018, p. 16). Mas a autora, ao tecer comentário sobre a composição do Fundef, sustenta que o conselho institui-se "não só como instância de fiscalização, acompanhamento e controle da aplicação e da transparência de recursos, mas também da avaliação de dados enviados aos municípios e estados..." (p.53). Ou seja, a categoria fiscalização é nesse caso listada junto com o acompanhamento e o controle, o que reforça o problema indicado: os conselhos também como fiscalizadores de recursos financeiros. Contudo, vale esclarecer que, como a autora se refere à criação do conselho do Fundef, o suposto equívoco, provavelmente, foi induzido pela própria Lei Federal n. 9 9.424/1996.

Os registros contábeis e os demonstrativos gerenciais, mensais e atualizados, relativos aos recursos repassados, ou recebidos, à conta do Fundo a que se refere o art. $1^{\circ}$, ficarão, permanentemente, à disposição dos conselhos responsáveis pelo acompanhamento e fiscalização, no âmbito do Estado, do Distrito Federal ou do Município, e dos órgãos federais, estaduais e municipais de controle interno e externo. (Art. $5^{\circ}$ ) (grifo meu).

Tal distorção é corrigida pelo artigo 26 da Lei Federal citada, já que a fiscalização e o controle dos recursos do Fundeb serão exercidos:

I - pelo órgão de controle interno no âmbito da União e pelos órgãos de controle interno no âmbito dos Estados, do Distrito Federal e dos Municípios;

II - pelos Tribunais de Contas dos Estados, do Distrito Federal e dos Municípios, junto aos respectivos entes governamentais sob suas jurisdições;

III - pelo Tribunal de Contas da União, no que tange às atribuições a cargo dos órgãos federais, especialmente em relação à complementação da União.

1284 - Rev. Bras. Polít. Adm. Educ. - v. 37, n. 3, p. 1279 - 1299, set./dez. 2021 
Lima e Aragão também consideram a fiscalização como sendo atribuição dos conselhos que seriam “... responsáveis pela fiscalização da repartição, da transferência e da aplicação dos recursos do fundo público” (2010, p. 259).

Coutinho faz o mesmo e traz como atribuição do CACS a dimensão fiscalizadora.

\footnotetext{
...os entes federados subnacionais se viram forçados a criar, estruturar e manter um Conselho de Acompanhamento e Controle Social (Cacs), responsável pelo acompanhamento e fiscalização dos recursos... (2015, p. 126). (grifo meu)
}

Mas o contraponto, desenvolvido em relação aos trabalhos citados não pretende desconsiderar a importância dos mesmos para o fortalecimento dos CACS, e sim colocar em discussão a forma como o termo fiscalização é utilizado. Registre-se que, em todos os trabalhos, o CACS é indicado como instrumento de fortalecimento da democracia e de participação social. Na verdade, em certos momentos, os estudos parecem apontar para uma espécie de fiscalização social, categoria que pode ser conceituada em futuro breve e contribuir para um melhor ACS dos recursos públicos da educação no Brasil via conselhos.

A seguir, serão abordados alguns aspectos da realidade do CACSFUNDEB/DF com o propósito de indicar as suas limitações e, por conseqüência, a sua missão quase impossivel para realizar o acompanhamento e controle social dos recursos do FUNDEB, do PNATE e do PAR no âmbito do Distrito Federal.

\section{ACOMPANHAMENTO E CONTROLE SOCIAL DOS RECURSOS DO FUNDEB: MISSÃO QUASE IMPOSSÍVEL 1}

A Lei 11.494/2007 (Lei de regulamentação do FUNDEB) estabelece que é atribuição dos conselhos "O acompanhamento e o controle social sobre a distribuição, a transferência e a aplicação dos recursos..." (art. 24) do Fundo.

Como no DF não existem municípios, a (re)distribuição dos recursos do FUNDEB não tem o mesmo impacto que nos outros entes federados. Na capital da república, o GDF é responsável pela manutenção e desenvolvimento do ensino (MDE) de todas as etapas e modalidades da educação básica. Já em relação à aplicação dos recursos, há potencialmente muito espaço para a atuação do CACS. O problema é que as garantias previstas na legislação do Fundo de acesso a documentos e a dados não têm resultado em fortalecimento do acompanhamento e o controle social (ACS) dos recursos. A esse respeito, é interessante analisar alguns excertos dos marcos legais e relacioná-los com a realidade vivenciada pelo Conselho no DF. A Lei 11.494/2007, por exemplo, estabelece que: 
Os registros contábeis e os demonstrativos gerenciais mensais, atualizados, relativos aos recursos repassados e recebidos à conta dos Fundos, assim como os referentes às despesas realizadas ficarão permanentemente à disposição dos conselhos responsáveis, bem como dos órgãos federais, estaduais e municipais de controle interno e externo, e ser-lhes-á dada ampla publicidade, inclusive por meio eletrônico. (art. 25)

O problema é que os registros contábeis e demonstrativos gerenciais existem em um formato incompatível com a lógica do ACS. Mas essa afirmação não tem como propósito questionar mecanismos e procedimentos de registro de verbas consagrados no âmbito da administração pública, mas sim fazer uma ponderação no que se refere ao seu uso por um conselho social. Essa disponibilização permanente dos registros contábeis e os demonstrativos gerenciais dos recursos repassados e recebidos à conta dos Fundos têm efeito basicamente nulo para os conselheiros, o que inviabiliza o uso de outra parte da Lei do Fundeb, a saber: "apresentar ao Poder Legislativo local e aos órgãos de controle interno e externo manifestação formal acerca dos registros contábeis e dos demonstrativos gerenciais do Fundo" (inciso I, art. 25). Como apresentar uma manifestação formal acerca de registros elaborados para outros propósitos e que dialogam pouco ou nada com a natureza do CACS? Já a Lei Complementar Distrital n. ${ }^{\circ} 793 / 2008$, no inciso III do artigo $6^{\circ}$, estabelece que é atribuição do CACS-Fundeb/DF “examinar os registros contábeis e demonstrativos gerenciais mensais e atualizados relativos aos recursos repassados ou retidos à conta do Fundo". Se já é complicado entender os tais registros contábeis e demonstrativos gerenciais dos recursos do Fundo, como elaborar manifestação e examiná-los?

Obviamente, o fortalecimento do ACS também exige certo grau de aproximação com dados e informações disponibilizadas pelo governo, sendo um exemplo disso o Relatório Resumido de Execução Orçamentária (RREO), disponibilizado pela Secretaria de Economia. O CACS-Fundeb/DF tem acompanhado bimestralmente, desde outubro de 2018, os recursos do Fundo inseridos nesse relatório, o que já é uma boa iniciativa, porém insuficiente, até porque nesse documento os dados são bastante genéricos, sendo possível visualizar apenas os valores totais previstos, a receita e a despesa de cada um dos impostos que compõem o Fundeb. Já outro documento disponibilizado internamente pela SEEDF, o Quadro de Detalhamento de Despesa (QDD), é um amontoado de valores pulverizados. Tem-se então o REEO genérico demais e o QDD, pelo contrário, muito específico, portanto, distantes das necessidades do CACS em termos de ACS. Ou seja, não se trata de ser genérico ou detalhado, mas sim adequado a um conselho dessa natureza. 
Em síntese, os registros contábeis e os demonstrativos gerenciais, imprescindíveis para os setores técnicos do governo que são responsáveis pelas prestações de contas e também para os órgãos de controle interno e externo, tendem a ser bastante limitados para o CACS.

Os mesmos argumentos podem ser usados no que se refere ao inciso III do artigo 25 da Lei 11.494/2007, o qual estabelece que o CACS poderá:

III - requisitar ao Poder Executivo cópia de documentos referentes a:

a) licitação, empenho, liquidação e pagamento de obras e serviços custeados com recursos do Fundo;

b) folhas de pagamento dos profissionais da educação, as quais deverão discriminar aqueles em efetivo exercício na educação básica e indicar o respectivo nível, modalidade ou tipo de estabelecimento a que estejam vinculados;

c) documentos referentes aos convênios com as instituições a que se refere o art. $8^{\circ}$ desta Lei [instituições comunitárias, confessionais ou filantrópicas sem fins lucrativos - ICCF].

Em relação à alínea "a”, a requisição resultaria na disponibilização do processo completo via Sistema Eletrônico de Informação (SEI) com centenas de páginas, despachos extremamente técnicos e, por vezes, confusos. Ou seja, seria pouco útil para um conselho de natureza social. Claro que o CACS poderia eleger algumas licitações e acompanhar os processos em termos dos empenhos, liquidações e pagamentos de obras e serviços custeados com recursos do Fundo, mas para isso exigiria uma infraestrutura que não existe.

No que tange à alínea "b", trata-se de um documento mais adequado para o fortalecimento do ACS, pois ao ter acesso às folhas de pagamento dos profissionais da educação que estão em efetivo exercício, o CACS poderia averiguar de forma relativamente rápida se os recursos do Fundo estão sendo usados de acordo com o que estabelece a lei. Obviamente, em função da existência de mais de 35 mil profissionais efetivos e quase 9 mil professores contratados temporariamente (outubro de 2020), o conselho teria que fazer tratamento mínimo dos dados, o que também exigiria infraestrutura adequada, o que não é o caso.

Ainda em relação à alínea "b", e a título de exemplo, o CACS-Fundeb/ DF não conseguiu, em 2019 e 2020, obter informações sobre o cumprimento ou não por parte do GDF do artigo 22 da Lei 11.494/2007 que estabelece que "pelo menos $60 \%$ (sessenta por cento) dos recursos anuais totais dos Fundos serão destinados ao pagamento da remuneração dos profissionais do magistério da educação básica em efetivo exercício na rede pública". Em resposta a ofício enviado pelo Conselho, a SEEDF respondeu que não é possível gerar relatórios com as informações solicitadas. O setor ainda anexou à resposta um documento 
com os totais empenhados, liquidados e pagos das mais diversas categorias (ativos, inativos, pensionistas, jetom, ressarcimento de despesas de pessoal requisitado, etc.), provavelmente essencial para o governo, mas que não atende ao que foi solicitado. A impressão é que a resposta foi emitida de forma burocrática e sem a devida atenção, o que mostra como os conselhos dessa natureza são tratados pelo poder público.

Já em relação à alínea "c", que estabelece que o CACS poderá requisitar documentos referentes aos convênios com as instituições comunitárias, confessionais ou filantrópicas (ICCF), tal prerrogativa não foi usada até o momento pelo conselho. $\mathrm{Na}$ verdade, o CACS-Fundeb/DF optou por acompanhar parte dessas instituições por intermédio de visitas, exatamente às escolas que foram contempladas com os prédios públicos construídos pelo Programa Nacional de Reestruturação e Aquisição de Equipamentos para a Rede Escolar Pública de Educação Infantil (Proinfância). Das 52 unidades que foram entregues às ICCF, os conselheiros visitaram, em 2019, o total de 29.

$\mathrm{Na}$ atual realidade do CACS-Fundeb/DF, talvez não seja exagero afirmar que as visitas in loco nas instituições escolares foram ações que mais fortaleceram o ACS em 2019. Motivo: foram bem organizadas e com o preenchimento de formulários elaborados pelos próprios conselheiros e à luz da realidade local. Durante essas visitas foi inevitável o diálogo entre conselheiros e membros da comunidade escolar, seja de maneira mais formal com base nas perguntas dos formulários, seja em conversas informais, mas que foram muito esclarecedoras acerca do impacto da política pública no mundo real.

Nesse sentido, o ACS dos recursos do Fundeb no DF acontece pouco por intermédio dos elementos mais técnicos que constam na Lei 11.494/2007. Mas tendo em vista a necessidade do ACS também ser fortalecido por intermédio de análise do relatório de prestação de contas da execução do Fundeb, que deveria ser elaborado pelo GDF, sugere-se que o Tribunal de Contas do Distrito Federal (TCDF) determine que o tal relatório leve em consideração a natureza do CACS e estabeleça parâmetros para tal. Obviamente, é interessante que isso seja feito em diálogo com o CACS e o GDF.

\section{ACOMPANHAMENTO E CONTROLE SOCIAL DOS RECURSOS DO PNATE: MISSÃO QUASE IMPOSSÍVEL 2}

A Lei 11.494/2007 estabelece que o CACS deve "acompanhar a aplicação dos recursos federais transferidos à conta do [PNATE]... e, ainda, receber e analisar as prestações de contas....” (Art. 24, \13,) 
É importante perceber que não consta a expressão acompanhamento e controle social (ACS), e sim acompanhamento da aplicação dos recursos federais do PNATE. Além disso, as razoáveis garantias, estabelecidas pelo Artigo 25 da Lei 11.494/2007, para um melhor ACS dos recursos do Fundeb não se aplicam ao PNATE (disponibilização de registros contábeis e demonstrativos gerenciais; convocação do Secretário de educação para esclarecimentos; requisição de documentos de licitação, empenho, liquidação e pagamento, etc.). A única exceção nesse artigo é o que consta na alínea b do inciso IV, que cita o serviço de transporte escolar, mas mesmo assim não se sabe ao certo a qual transporte escolar a lei se refere, se ao geral ou aquele limitado aos recursos do PNATE.

Mas o artigo $5^{\circ}$ da Lei 10.880/2012 determina que:

“o acompanhamento e o controle social sobre a transferência e aplicação dos recursos repassados à conta do PNATE serão exercidos (...) pelos conselhos previstos no $\ 13$ do art. 24 da Lei n. ${ }^{\circ} 11.494$, de 20 de junho de 2007”' (BRASIL, 2012).

Ou seja, na lei de criação do PNATE, aparece o ACS como atribuição do CACS. Além disso, essa lei resolve a omissão da Lei do Fundeb em relação aos mecanismos mínimos para o ACS dos recursos do PNATE, inclusive com prerrogativas fundamentais no que tange à requisição de dados e informações:

$\int 3^{\circ}$ Os Conselhos a que se refere o caput deste artigo $\left[5^{\circ}\right]$ deverão acompanhar a execução do PNATE (...), podendo, para tanto, requisitar (...) dados, informações e documentos relacionados à utilização dos recursos transferidos. (grifo meu)

Por que esse detalhamento não consta na Lei 11.494/2007? Eis aqui algo a ser corrigido na lei de regulamentação do novo FUNDEB, sob pena das atribuições do CACS ficarem pulverizadas em diferentes legislações, o que pode gerar confusão.

Mas existe ainda outro problema: os recursos transferidos pelo governo federal via FNDE para esse programa são executados juntamente com os recursos próprios do GDF para o transporte de todos os estudantes. Isso, na prática, inviabiliza que o CACS acompanhe a aplicação dos recursos federais transferidos à conta do PNATE e afirme com segurança se os valores estão sendo usados para o transporte de alunos residentes em área rural, tal como estabelece o artigo $2^{\circ} \mathrm{da}$ Lei Federal n. ${ }^{\circ}$ 10.880/2004.

Portanto, a emissão do parecer conclusivo é feito basicamente sem a segurança que o caso requer. Nos últimos anos, a aprovação do CACS-FUNDEB/ DF tem se baseado: no fato do GDF aplicar no transporte público de alunos da 
educação básica pública um valor bem superior aos recursos repassados para o PNATE'; nas prestações de contas do GDF encaminhadas via Sigpc nos últimos anos (2016, 2017 e 2018) e aceitas pelo governo federal e pelos órgãos de controle.

Mas a própria base legal, nesse caso em nível de FNDE, gera certa confusão em relação ao tipo de aluno que deve ser considerado para o uso dos recursos do PNATE. O artigo $2^{\circ}$ da Resolução FNDE n. ${ }^{\circ}$ 5/2020 estabelece que o atendimento aos estudantes da educação básica como um todo deve nortear a aplicação dos recursos do PNATE, ainda que destaque seja dado aos que residem em área rural.

Art. $2^{\circ}$ As seguintes diretrizes devem nortear a aplicação dos recursos do PNATE e a oferta de transporte escolar por parte dos estados, Distrito Federal e municípios:

(...)

III - pleno atendimento aos estudantes da educação básica pública, destacadamente aos residentes em área rural, que necessitem do transporte escolar para frequentar as instituições de ensino... (grifo meu)

Percebe-se que a Resolução citada procura sanar o impasse no que tange ao uso dos recursos do programa. Contudo, no artigo $5^{\circ}$, a resolução retoma a restrição ao estabelecer que "serão atendidos pelo PNATE os alunos matriculados na educação básica das redes públicas, estaduais, municipais e distrital residentes em áreas rurais...".

Vale destacar também o termo "exclusivamente" no artigo 14 desse mesmo documento:

Os veículos e embarcações mantidos, mesmo que parcialmente, com recursos do PNATE, deverão ser utilizados exclusivamente no transporte de alunos da educação básica pública, residentes em área rural.... (grifo meu)

Atente-se ainda que esse artigo determina que "os veículos e embarcações mantidos, mesmo que parcialmente com recursos do PNATE", serão de uso exclusivo dos residentes em área rural. Ou seja, a restrição é bem clara.

Mas o contraponto feito aqui não tem como propósito questionar o direito ao transporte escolar pelos alunos da rede pública como um todo ou sugerir que sejam realizados contratos específicos para o transporte apenas dos alunos residentes em área rural, até porque isso provavelmente oneraria muito a prestação do serviço. A ideia é indicar os limites do CACS-FUNDEB/DF no que se refere ao ACS dos recursos canalizados via PNATE para os estudantes residentes em áreas rurais. 
Mas além da execução conjunta dos recursos, há também outros desafios para que o CACS realize o devido ACS: falta de acesso à prestação de conta ao longo do ano; prazo bastante curso para análise e emissão de parecer conclusivo; além do complexo sistema de prestação de contas.

Em relação ao acesso à prestação de conta, o CACS só pode visualizá-la no Sistema de Gestão de Conselhos (Sigecon) após envio pela SEEDF e liberação pelo FNDE. Atente-se que tal procedimento, de acordo com as resoluções do FNDE, deve ser feito, em condições normais, até 28 de fevereiro do ano subsequente ao repasse; apenas depois é que o CACS tem acesso à infinidade de documentos e informações lançadas no sistema e por apenas 45 dias, período que pode ser prorrogado por mais 15 . Porém, esse prazo não é o problema mais grave, até porque o FNDE tem sido compreensivo em relação a essa questão ${ }^{4}$, e sim o fato do CACS não ter acesso às prestações de contas ao longo do processo de execução dos recursos. Seria interessante que o Sistema de Gestão de Prestação de Contas (Sigpc) fosse alimentado de forma mais eficiente pela SEEDF e que o CACS o acessasse durante todo o ano.

Quanto à complexidade do sistema de prestação de contas, é preciso afirmar e enfatizar que o Sigpc não leva em consideração a natureza do CACS. Seria interessante que adaptações e ajustes fossem realizados, pelo menos com a criação de um espaço com informações mais diretamente relacionadas ao ACS. Sugere-se que isso seja feito após consulta aos conselhos de todo o Brasil, por intermédio de reuniões técnicas com formato e tempo adequados para que as demandas do CACS em termos de ACS sejam entendidas.

O fato é que sem acesso aos documentos referentes à execução dos recursos durante o processo, com prazo inadequado para analisá-la e com um sistema incompatível com a lógica de ACS do CACS, as emissões de pareceres conclusivos são meros documentos burocráticos. A esse respeito, vale citar o que consta no Sigecon na parte de orientações ao presidente do CACS: "é importante lembrar que o acompanhamento do Programa durante o ano é de extrema relevância para a consecução dos objetivos e para a melhoria do transporte escolar no município". Obviamente, isso não pode ser feito com base na lógica estabelecida atualmente, pois, a rigor, não há acompanhamento via sistema, e sim análise e emissão de parecer. Isso reduz a ação do Conselho do FUNDEB no âmbito social, tornando-o espaço mais de fiscalização contábil.

4 Em 2019, por exemplo, a SEEDF enviou a prestação de contas (ano referência: 2018), no dia 22 de março, e o FNDE a deixou disponível para a emissão do parecer do CACS até 14 de julho, ou seja, um prazo bem superior ao que o FNDE tem estabelecido nas suas resoluções. 
Obviamente, o CACS pode reprovar a prestação de contas no seu parecer conclusivo; na verdade, é o que essa gestão do CACS pensou em fazer para os recursos executados nos anos de 2017 e 2018, mas os conselheiros demonstraram sensibilidade para com a realidade enfrentada pelos alunos que dependem do transporte escolar. Porém, o debate e as decisões precisam ir além da reprovação ou aprovação da prestação de contas; é necessário encontrar formas que permitam ao CACS cumprir a sua atribuição de ACS dos recursos repassados à conta do PNATE de forma segura.

Por fim, seria interessante que as resoluções do FNDE usassem o termo fiscalização no que se refere à aplicação dos recursos financeiros do PNATE como competência do MEC, dos sistemas de controle internos do poder executivo e dos tribunais de contas, mas não do CACS como faz equivocadamente a Lei 10.880/2004: "a fiscalização de que trata o caput deste artigo deverá, ainda, ser realizada pelos Conselhos referidos no art. $5^{\circ}$ desta Lei na execução do PNATE..." $\left(\mathbb{S} 1^{\circ}\right.$, art. 10)

O CACS é induzido a fiscalizar, e isso tende a enfraquecer a sua atribuição de ACS, até porque este não dispõe legalmente de estrutura administrativa própria.

Os conselhos dos Fundos não contarão com estrutura administrativa própria, incumbindo à União, aos Estados, ao Distrito Federal e aos Municípios garantir infraestrutura e condições materiais adequadas à execução plena das competências dos conselhos e oferecer ao Ministério da Educação os dados cadastrais relativos à criação e composição dos respectivos conselhos. ( $\int 10$, inciso IV, art. 24, Lei 11.494/2007) (grifo meu)

Por fim, vale lembrar que a infraestrutura do CACS-FUNDEB/DF, disponibilizada pelo Governo do Distrito Federal (GDF), é muito precária. E mesmo que os executivos melhorem muito os termos dessa garantia, ainda assim reflexões e definições serão necessárias acerca de como o CACS realizará o ACS dos recursos repassados à conta do PNATE. É que insistir na fiscalização e na sua lógica, a qual é bem materializada na documentação disponibilizada via Sigpc, tende a enfraquecer as ações do CACS e até mesmo distorcer a sua natureza. O risco é torná-lo cada vez mais uma espécie de apêndice da fiscalização, o que, a rigor, é silenciar a voz da sociedade em relação ao PNATE. 


\title{
ACOMPANHAMENTO E CONTROLE SOCIAL DOS RECURSOS DO PAR: MISSÃO QUASE IMPOSSÍVEL 3
}

\author{
De acordo com a Lei Federal no 12.695/2012, o CACS/FUNDEB é \\ responsável pelo
}

Art. 10. O acompanhamento e o controle social [ACS] da transferência e da aplicação dos recursos repassados para a execução das ações do PAR, conforme Termo de Compromisso, serão exercidos em âmbito municipal e estadual pelos conselhos previstos no art. 24 da Lei no 11.494, de 20 de junho de 2007. Parágrafo único. Os conselhos a que se refere o caput analisarão as prestações de contas dos recursos repassados aos entes federados e encaminharão ao FNDE demonstrativo sintético anual da execução físico-financeira, com parecer conclusivo acerca da aplicação dos recursos. (grifo meu)

Em relação ao ACS dos recursos do PAR, é fundamental destacar que, embora o CACS-Fundeb/DF tenha acesso ao Sistema Integrado de Monitoramento do Ministério da Educação (Simec), os dados e informações são muito bem organizados, mas para servir à lógica da prestação de contas pelo poder executivo.

Nesse sentido, a análise das prestações de contas e o devido encaminhamento ao FNDE do "demonstrativo sintético anual da execução físico-financeira, com parecer conclusivo acerca da aplicação dos recursos" é missão quase impossível, sobretudo porque, em outubro de 2020, existiam 26 termos de compromisso em vigor que resultaram em repasse de $\mathrm{R} \$ 74.590 .628,98$ e 30 novos firmados no valor de $\mathrm{R} \$ 21.177 .341,78$, mas ainda sem repasse. Ou seja, um valor potencial de mais de 95 milhões de reais "pulverizados" em 56 termos de compromisso. Mas existe ainda outro elemento que precisa ser levado em consideração para indicar as limitações acerca das ações do CACS no DF: a quantidade de reprogramações dos recursos do PAR, no caso 162 vezes, tendo com referência apenas os 26 termos que receberam repasses.

Para evidenciar melhor a dificuldade do CACS-Fundeb/DF em relação ao uso do Simec como elemento de fortalecimento do ACS dos recursos repassados via PAR, vale destacar alguns dados referentes ao termo de compromisso n. ${ }^{\circ}$ 4858/2012, o mais antigo dentre os que foram inseridos nesse sistema. Valor empenhado de $\mathrm{R} \$$ 34.225.889,16 e pagamento efetivado de $\mathrm{R} \$ 33.605 .389,16$ até a primeira semana de outubro de 2020. A complexidade já é anunciada no objeto do termo: equipamentos para climatização das escolas de ensino fundamental (ventilador e/ou condicionador de ar); mobiliário para as salas de aula de ensino fundamental (EF) e médio (conjunto aluno e professor); projetor multimídia para as escolas; tablets educacionais para professores que atuam no ensino médio. 
Até outubro de 2020, seis contratos tinham sido gerados e com uma quantidade impressionante de unidades adquiridas. Exemplo disso é o mobiliário para o EF com 138.294 conjuntos (aluno e professor). E esse total aumenta quando desagregado por bens específicos (cadeiras, mesas, etc.).

Além disso, o Simec permite que o CACS visualize a forma de contratação (licitação própria ou adesão à ata). Nessa parte do Simec é possível acessar as abas: forma de contratação, monitoramento, notas fiscais, pagamentos efetuados e pendências/finalizar. A aba monitoramento é a única que parece atender, e ainda assim de forma relativa, à lógica de ACS do CACS, pois permite visualizar as quantidades previstas no termo, o que foi recebido e lançado, bem como o valor de referência, de aquisição e o montante total gasto em cada item. Já a aba notas fiscais é a mais perfeita materialização do que foi afirmado antes em relação ao formato para atender ao poder executivo e aos órgãos de controle. Logo em seguida, aparece a aba pagamentos efetuados que, no caso desse termo, não havia lançamentos, sendo preciso acessar outra parte do Simec, intitulada $P A R$, e não o PAR 2011-2014, ou seja, uma complexidade a mais nas dificuldades já apontadas. Quanto à aba de pendências/finalizar há um espaço chamado visualizar resumo da prestação de contas, no qual é possível acessar todos os detalhes da execução física e financeira. $\mathrm{Na}$ parte da execução física, dentre as várias informações distantes da realidade do CACS, pode-se acessar dados precisos acerca da distribuição dos bens e onde cada um se encontra, o que permite ao conselho, caso seja do seu desejo, realizar visitas in loco para a checagem, obviamente por amostragem ou em função de alguma denúncia.

Um termo de compromisso como esse deixa claro o abismo entre o CACS e o uso do Simec para o fortalecimento do ACS, até porque não se pode esquecer da precária infraestrutura administrativa disponibilizada pelo GDF.

Mas há outro aspecto que precisa ser considerado no que se refere às atribuições do CACS junto aos recursos repassados via PAR: a incerteza em relação aos termos de compromisso que serão objeto de análise para emissão de parecer. Até outubro de 2020, o CACS-FUNDEB/DF tinha analisado e emitido parecer conclusivo de apenas um termo de compromisso, o de n. ${ }^{\circ} 6103$ de 2012, cujo objeto era a aquisição de veículo acessível padronizado. O CACS foi avisado pelo FNDE apenas 60 dias antes do prazo final para emissão de parecer conclusivo. Analisar as prestações de contas e enviar "demonstrativo sintético anual da execução físico-financeira, com parecer conclusivo acerca da aplicação dos recursos" (parágrafo único, art. 10, Lei 12.695/2012) nesse prazo significa romper com a lógica do razoável. Se o CACS tivesse sido avisado já na origem do termo citado, no caso em 2012, o parecer conclusivo poderia ser resultado de um ACS de várias gestões de conselheiros, com os mais diversos registros e 
análises parciais. Ter-se-ia, em vez de 60 dias, oito anos (2012 a 2020) ou mais para que o valor repassado $(\mathrm{R} \$ 1.056 .000,00)$ fosse submetido ao acompanhamento e controle social do CACS. Este poderia, não só conferir as aquisições feitas ao longo da tramitação do processo, mas também acompanhar as reprogramações e os seus motivos. Ou seja, o parecer conclusivo no final seria emitido com o mínimo de segurança. Segue o texto que aparece no final do parecer em questão.

O Conselho de Acompanhamento e Controle Social do Fundeb (CACS/ Fundeb), no uso das atribuições que lhe são conferidas pelo Artigo 10, da Lei $\mathrm{n}^{\circ} 12.695$, de 25 de julho de 2012, e considerando a análise e conferência de toda a documentação comprobatória das receitas e despesas relativas ao objeto do Termo de Compromisso em questão, resolve legitimar as contas regulares. (grifo meu).

Fica absolutamente claro o altíssimo nível de comprometimento dos conselheiros em relação à emissão do parecer. É óbvio que o CACS não considerou a análise e conferência de toda a documentação disponível, muito menos com avaliação diferenciada para as receitas e despesas. Esse texto padrão do FNDE é, para afirmar o mínimo, distante da realidade operacional dos conselhos.

É preciso enfatizar que as limitações do Simec para que o CACS melhore o ACS dos recursos repassados via PAR não pretende desqualificar esse sistema. Não se pode negar que ele é instrumento importantíssimo para avançar no cuidado com os recursos públicos, principalmente em tempos de perdas de direitos e ameaças quase que diárias aos valores republicanos e à própria democracia.

\section{CONSIDERAÇÕES FINAIS}

Esse estudo abordou as limitações do CACS-FUNDEB/DF no que se refere ao acompanhamento e controle social (ACS) dos recursos financeiros do Fundo, do PNATE e dos transferidos via PAR.

Sustentou-se que a fiscalização dos recursos financeiros da educação é fundamental, mas que deve continuar a ser de competência dos órgãos de controle, e não atribuição do CACS. Contudo, isso não significa afastamento completo desse conselho das estruturas de fiscalização já existentes; pelo contrário, devem ser estabelecidas conexões sólidas entre os processos de fiscalização e de ACS. Mas isso é diferente de tornar o CACS como apêndice de outros órgãos e com papel de assessoramento. A Resolução FNDE n. ${ }^{\circ}$ 05/2020 ilustra bem esse risco, na medida em que coloca o Conselho como órgão colegiado "de caráter fiscalizador, permanente, deliberativo e de assessoramento...” (inciso III, art. $4^{\circ}$ ). 
Para evitar o enfraquecimento do ACS é necessário que se garanta, pelo menos, infraestrutura administrativa adequada para o funcionamento do CACS já nos projetos de lei de regulamentação do novo Fundeb em tramitação no Congresso Nacional (PL n. ${ }^{\circ} 4372$ [Câmara] e 4519 [Senado] de 2020). Na verdade, seria mais interessante que na nova lei do FUNDEB fosse prevista legislação federal específica para regulamentação do Conselho do Fundo, com detalhes acerca da composição, atribuições, condições de funcionamento, formação dos conselheiros etc.

Ainda sobre essa possível lei de regulamentação do CACS, sugere-se que as atribuições sejam ampliadas, de forma que o Conselho seja responsável pelo acompanhamento e controle social de todos os recursos da educação, obviamente sem prejuízo de encaminhamentos específicos dos recursos do FUNDEB. Essa proposta se fortalece, não só devido à necessidade de um controle social sobre $100 \%$ do orçamento da educação, mas também devido à existência do Valor Aluno Ano Total (VAAT) que consta nas minutas de lei em tramitação.

Outro aspecto que o trabalho chama a atenção é a urgente necessidade do MEC aperfeiçoar os sistemas (Sigpc e Simec) utilizados pelo CACS para ACS dos recursos do PNATE e do PAR, de forma que estes "conversem" com a lógica do Conselho. Sem isso, esses sistemas continuarão excelentes, mas apenas para atender às necessidades do poder executivo e dos órgãos de controle.

No caso dos recursos do FUNDEB seria interessante o estabelecimento de protocolos básicos em termos de solicitação de documentos ao governo e aos órgãos de controle, sobretudo em função da demora por parte do poder público em responder às demandas do CACS. Sugere-se mesmo que isso seja feito de forma dialógica, inclusive com a participação dos tribunais de contas e dos ministérios públicos dos estados e do Distrito Federal. Tais protocolos devem contribuir para que o acompanhamento e controle social sejam cada vez mais aperfeiçoados. O ideal é que tais protocolos sejam submetidos a avaliações periódicas de forma a atualizá-los de acordo com as necessidades e a realidade.

Por fim, afirmar que "as atividades [dos conselheiros] exigem conhecimentos técnicos específicos, que se impõem ao papel político de controle social sobre os recursos que fiscalizam" (MADUREIRA E GOUVEIA, 2019, p.9) pode ser perigoso e fragilizar o CACS. Isso porque, se o papel meramente político do CACS não dá conta sozinho das complexidades que estão postas no âmbito do ACS dos recursos, a imposição de conhecimentos técnicos sobre o papel político desse conselho, a rigor, anularia a sua natureza. Portanto, entendese que o CACS precisa se concentrar na sua atribuição de acompanhamento e 
controle social dos recursos e fazer uso, tanto quanto possível, de conhecimentos técnicos por intermédio de assessoria técnica de alto nível que os governos deveriam disponibilizar.

\section{REFERÊNCIAS}

BORBA, Silvânia Lucia de Souza. Participação e controle social na Educação: onde está o fio condutor? Uma análise dos Conselhos de Acompanhamento e de Controle Social do FUNDEB. 2010. 167 f. Dissertação (Mestrado em Educação) - Universidade Federal de Pernambuco, Recife, 2010. Disponível em: <https://repositorio.ufpe.br/bitstream/123456789/3704/1/arquivo131_1. pdf $>$. Acesso em: 11 out. 2020.

BRASIL. Lei 9.424, de 24 de dezembro de 1996 (lei de regulamentação do Fundef). Brasília. Disponível em: http://www.planalto.gov.br/ccivil_03/leis/ 19424compilado.htm. Acesso em: 17 de outubro de 2020.

Lei 11.880, de 09 de junho de 2004 (institui o PNATE e o PEJA). Brasília. Disponível em: http://www.planalto.gov.br/ccivil_03/_ato20042006/2004/lei/110.880.htm. Acesso em: 17 de outubro de 2020.

. Lei 11.494, de 20 de junho de 2007 (lei de regulamentação do Fundeb). Brasília. Disponível em: http://www.planalto.gov.br/ccivil_03/_ato20072010/2007/lei/111494.htm. Acesso em: 17 de outubro de 2020.

Lei 12.695, de 25 de julho de 2012 (dispõe sobre o apoio técnico ou financeiro da União no âmbito do PAR). Brasília. Disponível em: http://www. planalto.gov.br/ccivil_03/_ato2011-2014/2012/lei/112695. Acesso em: 17 de outubro de 2020.

/MEC/FNDE. Resolução n. ${ }^{\circ}$ 05, de 08 de maio de 2020 (estabelece os critérios e as formas de transferência de recursos financeiros do Programa Nacional de Apoio ao Transporte do Escolar-PNATE.). Disponível em: https:/ / www.fnde.gov.br/index.php/acesso-ainformacao/institucional/legislacao/. Acesso em: 17 de outubro de 2020.

/Câmara Federal. PL n. ${ }^{\circ}$ 4372, de 27/08/2020 (regulamenta o novo FUNDEB). Brasília. Disponível em: https://www.camara.leg.br/proposicoes. Acesso em: 17 de outubro de 2020. 


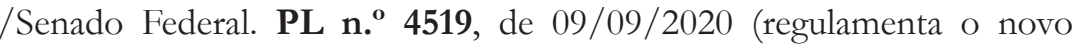
Fundeb). Brasília. Disponível em: https://www25.senado.leg.br/web/atividade/ materias/-/materia/144627. Acesso em: 17 de outubro de 2020.

COUTINHO, Henrique Guimarães. Os conselhos de acompanhamento e controle socialdo Fundeb e a gestão municipal da educação: um estudo em municípios nordestinos. 2015. 220 f. Tese (Doutorado em Educação) Universidade Federal de Pernambuco, Recife, 2015. Disponível em: <https:// repositorio.ufpe.br/handle/123456789/14951>. Acesso em: 11 out. 2020.

DICIONÁRIO ONLINE DE PORTUGUÊS. Disponível em: https://www. dicio.com.br/fiscalizacao/. Acesso em: 15 de out. de 2020.

GARELLI, Franco. Contrato Social. In BOBBIO, Norberto. Dicionário de Política. Brasília: Editora UnB, 1986.

DISTRITO FEDERAL. Lei Complementar n. ${ }^{\circ}$ 793, de 19 de dezembro de 2008 (criação do CACS-Fundeb/DF. http://www.educacao.df.gov.br/wpconteudo/uploads/2018/01/Lei-complementar-793-2008.pdf. Acesso em: 17 de outubro de 2008 .

LIMA, Ubirajara Couto; ARAGÃO, José Wellington Marinho de. O Conselho do FUNDEB e as práticas de participação institucionalizadas. In: TENÓRIO, Robinson Moreira; SILVA, Reginaldo de Souza (Org.). Capacitação docente e responsabilidade social: aportes pluridisciplinares. Salvador: EDUFBA, 2010, pp. 259-273. Disponível em: http://books.scielo.org/id/329/pdf/ tenorio-9788523208912-16.pdf. Acesso em: 11 out. 2020.

MADUREIRA, Maria Stael Madureira; GOUVEIA, Andréa Barbosa. O Fórum do Fundeb: uma invenção paranaense na fiscalização dos recursos da educação. FINEDUCA - Revista de Financiamento da Educação, Porto Alegre, v. 9, n. $18,2019$.

PRIBERAM DICIONÁRIO (online). Disponível em: https://dicionario. priberam.org. Acesso em: 15 de out. de 2020. 
UMANN, Jorge Miguel Bonatto. O controle social e público da gestão financeira da educação através dos conselhos municipais em Triunfo/ RS: uma reflexão das relações governo e sociedade. 2008. 167 f. Dissertação (Mestrado em Educação) - Universidade Federal do Rio Grande do Sul, Porto Alegre, 2008. Disponível em: <http://hdl.handle.net/10183/15521>. Acesso em: 11 out. 2020.

\section{Francisco José da Silva}

Doutor em Educação pela Universidade Federal do Rio Grande do Sul (UFRGS) Professor da Secretaria de Estado de Educação do Distrito Federal/EAPE

Presidente do Conselho de Acompanhamento e Controle Social do FUNDEB do Distrito Federal (CACS-Fundeb/DF).

E-mail: manoonam2br@yahoo.com.br 